\title{
Retelling of Assamese Folktales from a Feminist Perspective: A Reading of Tejimola and the Tale of Kite Mother's Daughter
}

\author{
AnkurJyoti Talukdar ${ }^{1}$, Anuradha Gogoi ${ }^{2}$ \\ ${ }^{1}$ Research Scholar, Department of Assamese, Gauhati University \\ ${ }^{2}$ Student, Department of English, Cotton University \\ E-mail- ${ }^{1}$ ankurjyoti@gauhati.ac.in, ${ }^{2}$ anuradhagogoi3@gmail.com
}

\begin{abstract}
Assam is a diverse land and so does it has a diverse expanse of folktale stories that widely shows the Assamese culture, the lifestyle and also its typical society. After reading the narratives of which has been taken in this research paper, the issue of women in Assamese folktales can be seen a matter of study and research, taking into consideration the aspects such as- position of women in Assamese society, identity of women, woman-woman relationship and women in the realm of class structure, and along with this a question definitely arises that do women have any hold of power in a society dominated by men and do they have any influence over the decision making aspects of men in a patriarchal society. The re-telling of Tejimola and The Tale of the Kite's Daughter narratives is done with a feminist point of view where the role of the female characters emerge in a contemporary manner and not as what had been thought and said in earlier times. The main motive is to highlight how the women emerge as a strong persona in the patriarchal domain, although their age-old interpretations project them as weak, inferior and maledependant.
\end{abstract}

Keywords

Assamese, Folktales, Feminist Perspective, Women, Society

Article Received: 10 August 2020, Revised: 25 October 2020, Accepted: 18 November 2020

\section{Introduction}

Folktales have probably been as old as mankind and are an integral part of every culture since ages. Indian folktales are diverse because it comes from a diverse land of religions, languages and cultures. Indian folktales imbibe moral values and these are ancient stories that have been passed on from generation to generation, making a perfect mixture of traditional values and present day generation, both seem to be repelling each other but folktales are the one that bind them into one. As a Discipline, Folktales are a particular division of Folklore and they generally are stories that are passed down from generations to generation. The subject matter of folktales in modern times is a mixture of traditionally obtained and orally transferred literally and a custom of subculture within literate and technologically advanced societies.

Folktales are not to be regarded as a simple moral and entertaining narrative for the audience, especially children. Although it is regarded as a means of social conditioning, it is also a reflection of the society and their ideologies. It has within its narrative structure, an element of protest and open endedness which makes the audience question the accepted social structures by making them reflect and thereby opening up the horizon of the individual's imagination. Most folktales do not have any fixed source of origin or authorship as a result of which several versions of the same tale exist with variations. Folktales are not a single individual's creation but created and revised by several individuals, across generations adding more character and dynamism to the tale so that the relevance and validity of the tale can be maintained when met by new and different generations whose desires and needs are different and growing. Folktales should not be read as a relative situation but as a mode that attempts to talk about universal ideas and situations that seek to teach humanity lessons of life. Therefore, folktales have a greater social responsibility that makes it an important area of study whose scope for research is opening up further with every step it is taking as an organized discipline in the modern times to arrive at a world of unattainable truths and knowledge

North-East, just like its unexplored beauties has many myths and folktales. There are numerous tribes and communities inhabiting the Northeast India and each of them have their enchanting folktales which are mysterious and unheard have beauty hidden in them to be foretold again and again. Assam has always been a powerhouse of folktales, just like the other states of Northeast India that are still loved by younger generations and are passed on. Assam is a diverse land and so does it has a diverse expanse of folktale stories that widely shows the Assamese culture, the lifestyle of Assamese people and also its typical society

\section{Objective}

To put it in a nutshell, the main objectives of the proposed study are:

a) $\quad$ To explore the representation of women in literary oral tradition, in the domain of patriarchy.

b) To understand and highlight the role of women in marriage and their importance within the family, through folktales.

c) To analyse a variety of themes such exploitation of women, inequality, evils of the society in the light of a woman's life.

d) To critically evaluate the folktales taken in the proposed study. 


\section{Source}

Since in the Assamese world there are endless folktales, it would be unfair to take and handle everything and not justify them in a proper manner, which is why only a few but canonical works have been taken for the sake of feasibility so as to stick to the most prominent ones such as stories from "Burhi Aair Sadhu" and "First Sun's stories: Unusual Stories from Northeast", so that a retelling can be more logical and interpretable. It is to be mentioned that the folktales taken in this research paper are translated from Assamese to English, most of which are translated by $\mathrm{Mr}$. Jnanabhiram Barooah in 1915. We know that there are several versions of one tale available all over the place but the mentioned translations have been found more authentic and thereby taken in as a primary source of study.

\section{Methodology}

The research design will be a qualitative analysis of the texts, explanatory in nature. Brief study on the folktales of Northeast India and Assam is taken up. Emphasis on the two folktale stories will be the goal. Basing the reading of primary sources from a feminist point of view, secondary sources are explored. Secondary sources in print and web sources in the form of books, articles and essays are consulted. In order to get familiarized with the topic of discussion, bibliographies contained in books, journals, articles and dissertations are explored and several libraries and information centres are visited by the researcher. We shall apply analytical methods to carry on the study.

\section{Discussion}

We all know that Feminism is a movement that is concerned with issues of gender difference and inequality and advocates that women must get equal rights as men for a better living world. History of feminism can be categorized in three waves: the first wave was in the 19th century and early $20^{\text {th }}$ century. The second wave came into being in the $1960 \mathrm{~s}$ and 1970s. The third wave stretches from the $1990 \mathrm{~s}$ and is prevalent today.

The word 'feminism' and its concept are quite new to Assamese readers. It is very important to trace back the root for the rise of Feminism in Assam. Women have been facing issues like oppression, inequality since time immemorial and the folktales of Assam witnesses that in the form of fictional children stories. We can say that even if these stories are taken lightly and are narrated to children, they act as a force in the moulding the thought of a person from a budding stage and that is why the age old norm of suppressing women has existed. Leaders like Mahatma Gandhi and Raja Rammohan Roy tried to give wings to many new ideas regarding the empowerment of women. According to them, men and women must get the same privileges and rights from freedom. In Assamese society, from the beginning of $20^{\text {th }}$ century, women from many affluent families got formal education mainly at home and eventually women were no longer restrained in homes and got exposure. It was Anandaram Dhekial Phukan who was the torchbearer of the women's movement in Assam. After Phukan, Hemchandra Barua and Gunabhiram Baruah followed his footsteps. Gunabhiram Baruah favoured widow remarriage and was the first person in Assam to marry a widow in 1870. Gunabhiram Baruah along with Lakhinath Borkakati were the first to send their daughters to Calcutta to study in Bethune College. Feminism gained its first impulse when in 1920 Assam Association, a socio- political organization was merged with Indian National Congress and the discussion concerning the status of women in society was initiated with fresh stamina. Not a single female student was admitted in Cotton College till 1926. After the passing of the Child Marriage Restraint Act in 1929, Asom Mahila Samiti took strict measures against the social malady in Assam. Though the Assamese women became aware of their pathetic situation in society, the seeds of feminism were sown by a few male writers, in the realm of world literature; Condorcet gave his thoughtful ideas through his work entitled, "Admission of Women to Full Citizenship" (1790). "A Vindication of the Rights of Women" (1792), is another seminal work by Mary Wollstonecraft. The idea of women empowerment in Assamese literature was first introduced by Dandinath Kalita's "Sadhana" (1928). Another writer who felt the necessity of writing on the miserable state of women in society was Rajanikanta Bordoloi and he wrote "Rohdoi Ligiri" (1930) for that purpose. It can be said that the very concept of feminism might be new but the fire for its need started long back. Women had themselves not understood their worth and hence never seeked for their true honour and identity and chose to remain behind the curtain. In the Assamese folktales we see that there is no touch of the subject matter called "Equality for Women", which is far more different from what we see in the postmodern era. If we are to say that what gave rise to feminism, especially in Assam, then we are to trace back to times where women were represented in texts as inferior and were also treated so in reality with minimal or no major rights at all. Representation of women can be highlighted as the major cause behind the waves of feminism and also the folktales were untouched with the sensitive matter of how a woman must be treated and what her rights in a society are.

\section{Women's representation through the folktales.}

In the folktale Tejimola, the lead character Tejimola is socially or literally represented as a powerless little girl, voiceless, afraid and has no strong point of her own. Even if she is the main protagonist of her story, she is not seen or observed as a powerful persona. From an angle, Tejimola's stepmother emerges as a stronger persona than Tejimola because she is a woman of actions and is very much like a modern day woman who does things because of herself, her happiness and her rights. Traditionally or socially, women are often projected as cunning or evil (when they do something which society does not permit) which goes very well with the character of Tejimola's stepmother. She is an anxious woman, firstly because she does not have a child of her own and secondly because her husband is too fond of his daughter (Tejimola) and probably less attention is paid to the wife. But as a typical woman of earlier times (as it is a folktale said years ago), it is evident that she is also bounded by the norms of society and cannot go against her husband's words. Also we know that before feminism emerged as a matter of study, women were always on the negative side or 
in a derogatory manner; or as pure, voiceless, chaste women. In this context, Tejimola's step mother portrays the evil character, that is told literally and socially and the character of Tejimola is more pure and chaste, which again is a social and literal norm, most probably handed down by men in a society or the portrayal of women by male writers. The minimal numbers of women writers always found it difficult to fight against the male centric writing industry and voice their opinions and oppose the age old notions of women in a society and women in literature. Earlier women writers were not encouraged and their works were not appreciated because of the male dominance over writing industry. "For Western literary history is overwhelmingly male- or, more accurately, patriarchal-and Bloom analyses and explains this fact, while other theorists have ignored it, precisely, one supposes, because they assumed literature had to be male." (Gilbert and Gubar, 1979, p. 2025).

Again in another folktale, "The tale of the Kite's Daughter" (Chilonee Jiyekor Sadhu), we are told about a potter in a certain village who is wealthy, but sonless. His wife only bore daughters and that was a constant source of worry to him. Once after his wife got pregnant, the potter addressed his wife and said "if you delivered a daughter this timebetter look out- as sure as I'm Your Husband, I will sell you to the Nagas." (Barooah, 1955, p. 103). Such is the social representation of women in a society who lives every passing day of her life in the fear of her husband and the uncertainty of her life. She is not given the right to enjoy her motherhood and she trembles with fear of her husband with the thought of delivering a daughter again.

Also it is an age old societal norm that women have to adjust according to all the traditions and bind herself in a prison which she cannot escape with her own will and that prison is the prison of patriarchy. When the new born baby was born, out of fear, her mother threw her into the river in an earthen pot which was later discovered by a washer man, just as he was reaching the child, a kite (chilonee) pounced upon it and flew away. Later the little baby's childhood beauty captivated the kite and she decided to nurture the child as a mother. As time wore on, the child grew up into a charming lady.

It is a matter of fortune and misfortune altogether for the little girl that even if the girl escaped her unfortunate fate from her real parents, she is still brought up by the kite mother to get her married to a suitor. It is a common age old norm of the society that young girls are not to be kept home for a longer time. As a result she is married off to a merchant who already has seven wives. At the beginning he tries to woo her and the kite mother by bragging about his possessions and promising to make the kite daughter happy forever but in reality, from a critical and feminist point of view, it is a typical trait of men to get hold of things that they like and prefer. Power politics plays a game here. In the present times, when feminism is at its height and women are free to choose when to get married and are also free to choose their suitors. But these folktales tell us of a social representation of women where they have no opinion other than getting. Since they do not have earning sources, they think that getting married is the only option for them to have a living even if they have to adjust in the worst scenarios. Also in this folktale "The Tale of the Kite's Daughter", we see this age-old phenomenon that women in the earlier time lived to please their husbands. This is both represented socially and literally, many a times and over many folktales, or folk fiction. In this context we see how the other wives of the merchant burn in jealousy as they think they will no longer receive the love of their husband. It is also seen that the society allows the male to act superior which is evident from the part of the folktale where the 'chaitbihu' (chaitbihu is the main Assamese festival celebrated in the Assamese new year in the month of April) was approaching and the merchant gave five seers of cotton to each of his eight wives and asked them to make him clothes for the festival, adding that he would like to see who made it the best ones. Now, we see that Bihu is a festival of love and joy but the husband is trying to place a competition among his wives. From this it is also evident that somewhere the male character is the one responsible for invoking the feeling of jealousy and the hatred among the wives towards the new bride. Had he not asked for the best clothes and told that whatever they make would be lovingly accepted, and then there would have been no point of jealousy and hatred among the women.

By the end of the folktale, the other wives try to sell off the new bride to a fisherman and when the husband finds out about their misdeed, he asks them all to tell the truth and tells that he is going to put them to test in a minute. He ordered his men to dig a very deep and wide pit and had it filled with thorny bushes and twigs and had a thread fixed between its two sides, traversing the whole pit. He ordered the wives to go across the pit crawling over the thread. He said that if anyone is really innocent then nothing will happen to them and if on the other hand they are guilty, they will fall down and will be killed. Six of them failed to attempt but only the seventh wife succeeded as she was really innocent. The merchant had the six wives buried alive in the same pit and lived happily together with the seventh wife and the kite's daughter, who is his eighth wife.

From a feminist point of view, this act of the merchant (the husband) appears to be very harsh and unjustified. Just because he is the patriarch, the all-powerful, firstly he promised his wives to keep them happy, just as he did to the kite's daughter, but eventually marries one after another woman and as a result there is a clash between the women which brings us to the conclusion that women are a prey to patriarchy. In society, the narrative projected those wives as evil in the folktale but after all they are human beings and do not deserve to be killed so brutally. On the other hand, the kite's daughter who is shown as all innocent does not possess a voice as a protagonist. This is how the narratives in the literary arena work. As a protagonist, and most importantly as a woman, she should have opposed the brutal act of burying all the women alive, but she did not do it because, as projected by the society, she too is a presentation of a woman who lives to please her husband and has no voice in the society and is mostly treated like a decorative item in the house.

We see that the position of women and their treatment have been the same since generations, be it during the time of our ancestors or today, women are still made to subdue their voices and their very existence is not given much importance in the male chauvinistic society.

It is the literary representation of women in folktales that shapes the idea of women that they must be meek, poised, idolizing their husbands as God as we see in many 
Assamese folktales that the wives address their husbands as 'Bongohordeu', almost giving them a very high position. It is seen that men have always been the 'one' and women have always been the 'other', through literary representations. This binary is as old as human existence and will never cease to exist. No matter how much success a woman acquires, she will still be questioned and criticized, unlike a man, who will be appreciated and congratulated. Simon de Beauvoir in her work "The Second Sex" says that women as the 'Other' have always been explicit in the hierarchical ranking. She also explains how women were treated in the primitive societies and how men thought of women as their property in the advent of private property. Women rather than a human being were treated more like an object.

In these folktales, we see that the women characters lack confidence. They are portrayed in such a manner, orally, so that women in real life lose confidence and give up on themselves and start feeling that they have a very limited role to play in life. They are made to feel inferior and 'unproductive'. These orally transmitted stories definitely portray women that devote themselves to their husband, children, and their dreams unknown. This happened because women in real life did not have knowledge and what it means to be in power. In the realm of the literary world, the female authors initially did not get recognition, they were denied what they deserved and clear favoritism was done to the male authors. Even a piece of work where a woman is portrayed as a protagonist is criticized and denied in high terms.

As we all know that folktales are an oral representation of the society and therefore are easier to travel places from mouth to mouth. Folktales like Tejimola and The Tale of the Kite's Daughter have been told to countless people, a countless number of times, but the sad part is that the representation is still the same. People are least bothered to question the treatment and low position of women portrayed in the folktales, because we all understand one specific idea that this is how the society runs. But, the coming of feminism has changed the air quite a lot, if not completely.At Least now women know how to raise their voices. The treatment of women appears to be the same as earlier but the responses that come from women have emerged stronger and their voices louder. Even though weaker representations of women like Tejimola and the kite's daughter are sympathetic and connect to the common women, it is time to subvert these age old notions and question the representation of their characters and the whole of patriarchy. These societal or literary representations of women will never allow genuine equality between both the sexes, male and female. Simone de Beauvoir is of the idea that if women are to get equal status as men, then everything has to start anew, the viewpoints must be reviewed and a new system must be established.

It was socially considered that women earlier were more emotional than rational and did not have the intellectual capabilities of men. John Stuart Mill, in his essay "The Subjugation of women" argues that if women seem emotional, passive and political, it is because they have been brought up to be so. "There is never any want of women who complain of ill usage by their husbands." (Mill, 1869, pp. 25-26). Mill insists that until society treats men and women equally, it will be impossible to know the natural abilities of women, or whether there are inherent differences between the sexes. It is the representation of women in society that has restricted our minds too. Why do people always think and tell about the tragedies in the life of Tejimola and then end it with a happy ending. People are never stoked with the idea that what Tejimola is like as an individual, without her father or any male figure? Why was it so tough for her to stand up against her step mother when she was dying? All of these never come to our mind because our mind has been conditioned in this manner. We all have read books and stories where the male always comes to the rescue of the female and she is a helpless individual.There are only minimal works that we can count on fingers where women are made heroes in real sense. It is all because we know and learn what has been represented to us and therefore, the idea of women have been the same to the society, although the concept of feminism came up, because we live in a society where girls are now although educated but the parents` primary goal is to marry them off before they reach the age of thirty and are of the idea that they need a man to survive and live well in life. This real representation of society and the mindset of a patriarch is what we see in the mentioned folktales. Women to the literary world are an object to male chauvinistic society that cannot live on her own terms, where a man never leaves his work for the family but a woman has to; where the title of 'bread winner' is hardly given to a female but to a male: where women are still criticized for giving birth to girl child. Therefore, it is quite evident that changes have come in the society today, but somewhere the treatment and representation of women have gained only a very little change.

\section{Conclusion}

From the research paper, we find certain truths about the societal system and how it creates an order which eventually people are bound to follow. The status or position of women appeared to be very low in the past due to the strict patriarchal norms of the society and women were restrained within the four walls of the house. From the folktales taken in this research paper, it can be found that the prime reasons for the suppressions faced by women is due to lack of education and systematically composed male centric religious literature etc. . In these folktales it is observed that earlier women were subdued and their voices were suppressed because most of them did not have the privilege of studying and thus they were dependent either on their fathers before marriage or their husbands after marriage. Although Tejimola's stepmother was enraged and jealous of Tejimola, yet she could not show it in front of her husband out of fear as she was dependent. Same is the case with the potter's wife from The Tale of the Kite Mother's Daughter. Just because she is dependent on her husband, she is deprived of her own child. From a personal point of view it can be assumed that the oral tellers of these folktales must have been males and thus in the stories the concept of 'good woman' and 'bad woman' have taken place.

We all know that Northeast comprises myriad tribes and communities and there are many such tribes who are in favour of feminism within their belief system such as the 
Khasi tribe, the Garo tribe etc. and they run with the matriarchal order in the society where women have some sort of authoritative power. In their traditional folktales we will also find many stories where women are deprived and cry for their identity, but still there is some amount of consideration for women because the society runs or functions a bit differently from the mainstream Assamesesociety. In Assamese men may overpower women but in matriarchal societies women may lead to women's deprievations, in some way or the other women will suffer. In the folktales taken from the Assamese region, we find no traces of authority among women and its striking to realize that the other matriarchal societies of Northeast region have not much influenced the mainstream Assamese society. The mainstream Assamese is basically influenced by the norms of Northern India, with traditions of the Brahmanical caste. Not everyone belongs to the general caste but people tend to follow its norms since they have been at the top of the entire caste system and they claim to have all sort of knowledge and righteousness. Although the Assamese society has developed quite a lot in terms of thoughts and rigidity, especially for women; we still find that in many households men are given more privileges than women and marriage appears to be the last resort for many women.

In this study it is found that the central characters in the folktales totally resort to silence even after facing so many hardships in life. They do not rebel against the odds of patriarchy. But feminism advocates equality and justice for all. In a patriarchal society even though women like Tejimola's stepmother and the wives of the merchant in The Tale of the Kite's Daughter are portrayed as negative, they atleast resort to some action to do justice to themselves. Whatever they had done could be right or wrong but they did not limit themselves to silence, unlike the central characters who chose to live in misery until a man came to their rescue and thought that their life revolves around their husbands. The actions of the women who are characterised as negative in the folktales can be justified because they were deprived of their rights and were deprived as a basic human.

Even if they were wronged their voices were not heard and ultimately they were punished by the patriarchs, who assumed themselves to be the supreme authority in a society. The concept of 'good woman' and 'bad woman' has been made by society but nobody has ever questioned what makes a bad woman 'bad'. Also it is vividly found in the folktales that there is no space for rebel women in a patriarchal society, for e.g. the wives of the merchant were punished terribly where they had to give up their lives and Tejimola's stepmother was also punished, but none of their reasons for their actions were heard or understood. In this study, which is a retelling of the age old folktales, it is found that the concept of feminism can be understood more through the portrayed negative women characters.

Thus, "Retelling of Folktales from a Feminist Perspective: A Reading of Tejimola, and The Tale of Kite Mother's Daughter" tries to project the very idea that how the Assamese society has treated women since ages, being influenced by the mainstream Indian society and how patriarchy had made their lives miserable most of the times and how they were exploited innumerably. But we also can witness local influence in many of the folktales where women are treated with grace and honour, even the ratio is smaller. It can be traced that because of the cultural hegemony and influence of other parts of India with rigid norms for women, the Assamese society, in comparison to other states of Northeast, tends to portray or represent women more in a certain manner which is not really close to what we term as "equality" and hence we see the rise in feminism as a demand of the time. All these also tell us how power structure works and how the male centric society follows it to suppress women who speak up for themselves and the threat that follows.

\section{References}

[1] Barooah, J. (1955). Folktales of Assam. Lawyer's Book Stall, Guwahati

[2] Beauvoir, S. de. (2015). The second sex. Vintage Digital, New York

[3] Gilbert, S. M., \& Gubar, S. (Eds.). (1979). Infection in the sentence: The Mad Woman in the Attic. Yale University Press, London

[4] Mill, H. T. (1869). Subjugation of Women. (J. S. Mill, Ed.). Dover Publications. New York

[5] Sims, M. C., \& Stephens, M. (2005). Living folklore: an introduction to the study of people and their traditions. Utah State University Press, Utah

[6] Thompson, S. (1946). The folktale. Dryden press, New York 